\title{
Plant food supplement (PFS) market structure in EC Member States, methods and techniques for the assessment of individual PFS intake $\dagger$
}

\author{
Liliana Vargas-Murga, ${ }^{a}$ Alicia Garcia-Alvarez, ${ }^{a}$ Blanca Roman-Viñas, ${ }^{a}$ Joy Ngo, ${ }^{a}$ Lourdes Ribas-Barba, ${ }^{a}$ \\ Suzanne J. P. L. van den Berg, ${ }^{b}$ Gary Williamson ${ }^{c}$ and Lluis Serra-Majem ${ }^{d a}$
}

Received 23rd May 2011, Accepted 28th July 2011

DOI: $10.1039 / \mathrm{clfo} 10075 \mathrm{k}$

\begin{abstract}
The popularity of herbal products, especially plant food supplements (PFS) and herbal medicine is on the rise in Europe and other parts of the world, with increased use in the general population as well as among specific subgroups encompassing children, women or those suffering from diseases such as cancer. The aim of this paper is to examine the PFS market structures in European Community (EC) Member States as well as to examine issues addressing methodologies and consumption data relating to PFS use in Europe. A revision of recent reports on market data, trends and main distribution channels, in addition an example of the consumption of PFS in Spain, is presented. An overview of the methods and administration techniques used to assess individual food consumption as a starting point, including their uses and limitations, as well as some examples of studies that collect Food Supplement (FS) information, including herbal/botanical/plant-derived products are also discussed. Additionally, the intake estimation process of food nutrients is described and used to propose the PFS ingredients intake estimation process. Nationally representative PFS consumption data is scarce in Europe. The majority of studies have been conducted in Scandinavia and the UK. However the heterogeneity of definitions, study design and objectives make it difficult to compare results and extrapolate conclusions.
\end{abstract}

\section{Market structures in EC Member States of PFS}

Food supplements are regulated by Directive 2002/46/EC, known as the Food Supplements Directive, and may be marketed within the Community only if they comply with the rules laid down in this directive. ${ }^{1}$ The objective of the document was to harmonize EC rules across Member States, but does not provide for substances other than vitamins and minerals, such as amino and fatty acids, fibers, plants and plant extracts, to be used in FS and they continue being regulated by various national decrees. The manufacturer or the person placing the product on the market in the Member States territory is obliged to notify the competent authorities of these activities by forwarding a model of the label used. This process is free of charge in some European countries.

${ }^{a}$ Nutrition Research Foundation, University of Barcelona Science Park, Baldiri Reixac 4-8,08028 Barcelona, Spain.E-mail: fin@pcb.ub.es; Fax. +34 9340345 43; Tel: +34934034541

${ }^{b}$ Division of Toxicology, Wageningen University, Tuinlaan 5, $6703 \mathrm{HE}$ Wageningen, The Netherlands

${ }^{c}$ School of Food Science and Nutrition, University of Leeds, Leeds, LS2 9JT, UK

${ }^{d}$ Department of Clinical Sciences, University of Las Palmas de Gran Canaria, 35080 Las Palmas, Spain

$\dagger$ This paper forms part of the themed issue on Plant Food Supplements: regulatory, scientific and technical issues concerning safety, quality and efficacy.
The European herbal market is growing due to the interest in complementary and alternative healthcare therapies (e.g. acupuncture, ayurvedic medicine, chiropractor, homeopathy, naturopathy, traditional Chinese medicine, yoga), the increase in the elderly population, emerging efficacy studies from plants, including interactions and side effects, as well as consumers awareness about general health and well being.

\subsection{Market data}

Member States have a dynamic market for PFS, and in general for herbal products. Recent reports concerning the market data are published by Business Insights (BI), which cover the market for vitamins and minerals, herbs and botanicals, and sports and speciality supplements in Europe and the United States (US), and by Global Industry Analysts (GIA), which analyzes the worldwide markets for herbal supplements and remedies. ${ }^{2,3}$

According to BI, in the EC, the Nutrition and Health Claims Regulation (EC) $\mathrm{N}^{\circ} 1924 / 2006$ is highly controversial. To date, the European Food Safety Authority (EFSA) has published 1851 opinions on 4951 submitted claims covering reduction of disease to basic structure function claims. $91 \%$ of the claims with published opinions submitted under the 13(3) route have received a negative evaluation by EFSA.

The global herbal supplements and remedies market exhibited robust growth over the decade, with little or apparently no significant decline on account of the worldwide recession and is 
forecasted to reach US\$93.15 billion by the year 2015, according to GIA. The world market in fact, exhibited steady growth for the crisis-ridden period of 2008-2009 and beyond. Recession in the European economy and the increased capital requirements for registration under EC regulation of companies expanded the resources of small companies and provided opportunities for acquisitions in herbal supplement markets. In the US and Europe, herbal medicines represent a major share of the pharmaceutical market and are included in regular medicinal practice. However, the market is highly regulated and of difficult access, as companies need to pass rigorous tests before mass production.

Europe represents the largest regional market, accounting for the single largest share of the world market. Asia-Pacific and Japan make up the other important markets for herbal supplements on a global basis. In terms of growth rate, the Asia-Pacific market, led largely by China and India, is set to pave the way with the highest Compound Annual Growth Rate (CAGR) of $10.7 \%$ through 2015 . The market for herbal supplements varies by region based on factors such as consumer awareness, product availability and forms of delivery, product acceptance, and regional regulations. ${ }^{3}$

A study elaborated by the European Advisory Services (EAS) provide detailed data about the four largest EC Member States, in terms of sales, led by Italy which is closely followed by Germany, UK and France. ${ }^{4}$ Growth projections to 2010 provide an indication of the extent to which previous rapid growth cannot be taken as an indicator of future rapid growth. However, market growth is not expected to reach the levels achieved in the previous decade. The reasons for the market growth decrease might be due to changes of some important economic factors, for example market saturation. Other factors having a strong impact on the growth of the market of FS containing other substances might be the notification/authorisation of national requirements, restrictions on distribution channels and the extent to which the national authorities apply mutual recognition.

Referring to herbal ingredients, the EAS reports that ginkgo followed by echinacea, garlic and ginseng are the four most commercially important botanicals in the combined markets of seventeen EC Member States, although echinacea and gingko are part of the composition of products registered as medicines. The wide variations in the size of national markets are, in some cases, due to the regulatory origins.

\subsection{Market trends}

A major trend observed in the market is a shift from a single ingredient market to multiple ingredient-based medications for a particular condition. There is also an increased demand for herbal and botanical products in multi formula and combination packed format, as well as for chewable capsules and tablets. Multi-herbs dominate as the largest segment, capturing a significant share of the overall herbal supplements and remedies market worldwide. The segment is also forecasted to surpass other markets, having the fastest compounded growth rate of $9.0 \%$ over the analysis period (2000-2006). Soy and specialty herbs are also expected to display strong growth potential in the future. $^{3}$

Another important trend is seen in the type of consumer. According to the GIA, women, particularly in the middle-aged bracket, form the major consumer group owing to their growing health-consciousness, increased concern for diet, and enhanced attention towards preventive healthcare. In addition, there is a greater urgency to maintain healthy lifestyles, focusing on alternatives for conventional medicine and general health. Some of the health benefit for which consumers consider herbal and botanical supplements as natural alternatives include: hormone replacement therapy, prostate health, brain health and cognitive function, and joint and connective tissue health.

GIA reports that the importance of a healthy diet and lifestyle reigns in the minds of the consumer, which is not affected even by the financial crisis witnessed in almost every other product segment worldwide. In fact, the recession may have actually prompted increased preference for dietary supplements. Escalating prices, tighter budgets and high health care and lifestyle costs have actually driven consumers towards the more economical and perceived healthier and safer options of alternative medicine and dietary supplements for relief of physical and mental disorders.

\subsection{Distribution channels}

Direct sales and consumer sales channels or retailers are the two marketing techniques for PFS used by manufacturers, distributors and importers.

Direct sales includes mail order, e-commerce, multilevel marketing and medical \& alternative health practitioners, whereas consumer sales address drugstores, health/natural food stores, herbal shops, parapharmacies, pharmacies, supermarkets/ mass market, and among others, specialized shops (e.g. gym, hairdresser, healthcare institutions, sporting goods store).

According to GIA, there is an increase in the number of retail outlets along with e-commerce, coupled with efficient support and cooperation of medical and health professionals.

Mail order and internet sales are expected to continue growing as a result of the increasing number of internet websites selling PFS.

The common and widely distributed retail channels in the Member States are drugstores, health food stores, herbal shops, pharmacies and supermarkets. Most consumers prefer to buy PFS in herbal shops and pharmacies where they can receive advice on product benefits and dosage.

Multilevel marketing, also known as direct selling, party plans, relationship selling, person-to-person selling, and network marketing constitute another important channel. However, few are used by manufacturers/distributors.

Because consumer demand has increased greatly, larger pharmaceutical companies are entering the market, often by buying supplement firms. As a result, the structure of the market is changing and will continue to change as the PFS market matures.

\subsection{Case study: Spain}

FS are regulated in Spain by the Royal Decree 1487/2009, which adopted the total Directive 2002/46/EC, concerning FS. ${ }^{5}$ This decree includes labelling, composition and sale notifications of FS. There is neither an allowed nor prohibited list of botanicals, 
but mutual recognition is accepted in order to respect free market circulation.

The "White Book of herbal shops and medicinal plants" is a report about the situation of the Spanish herbal shop sector. ${ }^{6}$ The data about plants that can be used for FS or herbal medicine are not clearly differentiated. However, herbal medicine is not allowed to be sold in herbal shops. According to this report, the relevant findings are cited below:

- Herbal shops prefer to sell products of different brands $(87 \%)$ instead of selling only one brand $(11 \%)$ or their own brand $(2 \%)$.

- Herbal shops are the main retailers chosen by the consumers $(81 \%)$, while food stores, pharmacies and parapharmacies showed consumer choice prevalences of $4 \%, 1 \%$ and $4 \%$ respectively.

- The preferred location of herbal shops according to consumers is nearer to their homes $(58 \%)$ rather than their jobs $(23 \%)$.

- The top-selling products are FS (29\%) followed by weight control products $(28 \%)$.

\section{Methods for the assessment of individual PFS consumption}

The use of PFS is on the rise around the world; however, there are many problems associated with botanical research. These include among other problems, defining the concepts and selecting the appropriate study methods. The methodology used for the assessment of PFS consumption is an area that has been little explored at the public health level, and in essence consists of using existing dietary survey methods and procedures that have mainly been developed with the aim of evaluating the nutritional status of a population i.e. the intake of energy, macronutrients and/or micronutrients. For instance, in the USA, there are some routinely conducted surveys that obtain some (limited) information on dietary supplements including botanicals. ${ }^{7-9}$

The present section includes an overview of the methods and administration techniques used to assess individual food consumption as a starting point, including their uses and limitations. Moreover, some examples of studies that collect FS information, including herbal/botanical/plant-derived products, are described in terms of their assessment methodology. Finally, the methodology designed for data collection on PFS consumption in a six-European-country survey within the PlantLIBRA project (PLANT food supplements: Levels of Intake, Benefit and Risk Assessment), a project co-financed in the context of the 7th EU Framework Program (FP7 Ref. 245199) ${ }^{\mathbf{1 0}}$ is presented as an example of future needs in the assessment of these products.

\subsection{Methods for the assessment of individual food consumption - uses and limitations}

Dietary intake is a highly variable event which experiences significant changes depending on, for example, the day of the week and the season, based on an underlying pattern of consumption. Thus, within a week an individual can consume hundreds of different foods. Additionally, the interviewed person may not know exactly what he/she is eating and/or how much if he/she did not prepare the food. Both intake variation and the error inherent in its assessment method may affect the quality of results. ${ }^{11}$

The methods for collecting dietary information at the individual level are properly called food surveys ${ }^{11}$ and can be classified into two main groups: ${ }^{12}$

- Group 1) Quantitative daily consumption methods comprises recalls or records designed to measure the quantity of the individual foods consumed over a 1 day period, including single and repeated $24 \mathrm{~h}$ recalls and estimated and weighed food records. By increasing the number of measurement days, quantitative estimates of the usual intakes of individuals can be obtained, using the same instruments. The number, selection, and spacing of the days depend on the food intake, the nutrients of interest, the day-to-day variation in nutrient intake, and the level of precision required. Determination of usual intake is particularly critical when relationships between diet and biological parameters or chronic disease are assessed. Estimates of usual intakes are also needed to evaluate the prevalence of inadequate intakes.

- Group 2) Dietary history and the food frequency questionnaire - both obtain retrospective information on the patterns of food use during a longer, less precisely defined reference time period. They can be used to assess the usual intake of foods or specific classes of foods, and with modification, can also provide data on usual nutrient intakes.

$24 \mathrm{~h}$ recall. This method requires that the subject remembers and gives details of all foods and beverages consumed in the previous $24 \mathrm{~h}$, or the day before the interview. The interviewer normally uses dietary models, photographs or household measures to help the respondent quantify the physical amount of food and beverages consumed. It collects information not only on the food and the amount of it consumed, but also on the type of food (i.e. if processed, canned, etc.), the ingredients, recipes, the fats or oils used, spices, salt types, trademarks, vitamin supplements, etc., as well as the location (e.g. home, work, restaurant) and consumption time of each food. ${ }^{11}$

Repeated 24 h recalls. Twenty-four hour recalls can be repeated during different seasons of the year to estimate the average food intake of individuals over a longer time period (i.e. usual food intake). The number of $24 \mathrm{~h}$ recalls required to estimate the usual nutrient intake of individuals depends on the dayto-day variation in food intake within one individual (i.e. withinsubject variation). ${ }^{12}$

Estimated and weighed dietary records. The estimated dietary record (or food diary), is a prospective method, and consists of asking the respondent to complete a record for 3,7 or more days, of all the food and beverages he/she consumes at home and outside the home. This method requires that the respondent be instructed in advance with the help of models and/or household measures on how to detail the portions consumed. A variant of the estimated dietary record is the weighed dietary record in which, instead of describing the portion with household measures, the respondent weighs the food before eating and after, weighing the leftovers. The food diary assesses current intake. This method is very accurate, but requires great 
cooperation from the respondent, as the evaluation of several days can provoke fatigue and dietary changes. ${ }^{11}$

Dietary history. This method was developed by Burke and includes an extensive interview whose purpose is to obtain information on current and past eating habits and consists of one or more 24 hour recalls and a food frequency questionnaire. It requires a highly experienced dietician for its administration. The questionnaires designed to assess food intake in retrospective epidemiological studies such as the case-control studies are also called dietary history questionnaires. ${ }^{11}$

Food frequency questionnaire. Food frequency questionnaires consist of a closed list of foods on which the frequency of consumption (daily, weekly or monthly) over a specified period of time (i.e. 6 months, 1 year) is requested for each food item. The information collected is qualitative, although the incorporation for each food item of a standard portion size (semi-quantitative food frequency questionnaire) or the individual's own usual portion size (quantitative food frequency questionnaire) allow for the quantification of food consumed and also of nutrients. This method can be self-administered. ${ }^{11}$

Uses and limitations of food consumption assessment methods. Table 1 includes the uses and limitations of the methods described in section $1 .^{11}$

Administration techniques of food consumption assessment methods. Food consumption assessment methods can be administered using two main types of techniques:

- By interview. The interview can be personal or by telephone. Uses of these interview techniques include that they ensure the completion of all questions, allow you to use complex and multiple questions and to clarify questions that are not understood (although this can introduce bias), facilitate cooperation and can be applied in illiterate populations. Limitations include that they are costly and time-consuming and can introduce interviewer bias.

Table 1 Uses and limitations of the different food consumption assessment methods in individuals ${ }^{a}$

Uses

The administration period is short

- The procedure does not alter the individual's usual intake

- It is useful for any type of food pattern

- A single contact is sufficient

- Can be used in illiterate subjects

- Its cost is moderate

- High response rates

- Can estimate the individual's usual intake

Repeated 24 h recall

- It is difficult to accurately estimate the portion size

- Depends on the respondent's memory

- Trained interviewers are needed for its administration

- Limited application in children and the elderly

Dietary records (estimated and weighed)

Accuracy in the estimation or calculation of the portions consumed

- The procedure does not depend on the individual's memory

Dietary history

- The individual must be able to read, write and count

- Requires much time and cooperation by the respondent, especially the weighed dietary record

- Codification and analysis cost are high

Can give a more complete and detailed description of the usual $\mathbf{q}$ Requires a highly trained interviewer, usually a dietician and past dietary intake than the other methods

- Can be used in illiterate people

- It takes time and lots of cooperation from the interviewee

- The administration cost is high

- There is no standard way to do the dietary history

Food frequency questionnaire

- Can estimate the usual intake of an individual

- The development of the instrument (questionnaire) requires considerable effort and much time

Fast and easy to administer

- The habitual consumption pattern is not altered

Does not require trained interviewers

- Very low administration costs, especially if conducted by mail

- Ability to classify individuals into categories of consumption, useful in epidemiological studies
- Literacy of the subjects is required

- Doubtful validity of the estimated intake of individuals or groups with very

different dietary patterns to those of foods from the list

- Validity must be established for each new questionnaire and population

- Requires memory of eating habits in the past

- Low accuracy in the estimation and quantification of food portions

- Remembering of the diet in the past may be biased by the current diet

- The time and inconveniences to the respondent increase according to the number

of food items and the complexity of the food list and quantification procedures

- It is not useful in the elderly and children

- Little validity for most vitamins and minerals

- Does not allow assessment of intra-individual variation in intake, since only

a single measure is available

${ }^{a}$ Source: Adapted from Serra Majem, 2006 and Gibson, 2005. 
- Self-administration. The respondent completes the questionnaire by her/himself, which could have been handed out or posted to the respondent. Self-administration techniques have fewer uses/strengths e.g. absence of interviewer bias and low cost - and more limitations - they tend to be partially completed, can not be used for multiple and complex questions, is difficult to ensure understanding of the question, have a low response rate, and present restriction of subjects (literacy is required).

The limitations and advantages of each method and administration technique have to be placed in the context of their cost and quality of the information obtained. ${ }^{11}$

\subsection{Examples of studies that have collected FS including herbal/botanical/plant-derived food supplements}

Through the methods previously described, dietary surveys cannot detect certain vital concepts in nutritional assessment of a community, such as, among others, the consumption of FS (which include PFS). So far, dietary surveys merely include a series of structured questions about the use of these specific products retrospectively during a specified period, but the specific methodology for collecting information on their consumption is non-existent and at best is an adaptation and combination of different dietary surveys methods (see Table 2).

For example, in the National Health and Nutrition Survey (NHANES) survey 1999-2000, dietary supplement intake by US adults was assessed by asking participants during a home interview whether they had taken any vitamins, minerals, or other dietary supplements, including prescription supplements, in the last month. They were shown a card with examples of many types of supplements. Interviewers were asked to see participants' supplement containers, and they recorded the name and manufacturer of each supplement from the label. If the container was not seen ( 22 percent of the time), the interviewer asked for the exact name of the product or, if not known, the supplement type, for example, multivitamin or vitamin C. Participants were asked how long they had been taking this product, how often, and how much they took. Information on as many as 20 supplements could be recorded. ${ }^{13}$

In addition, EFSA's "Expert Group on Food Consumption Data" (EGFCD) recommends that, when reporting the use of supplements and medicines in a pan-European dietary survey for adults, "subjects should report the supplement name, the brand name, the strength and the amount taken". This would require a separate section in a diary or recall and the development of a specific dataset including nutritional supplements at the brand level. The long-term use of FS and medicines containing nutrients must be explored by means of ad hoc questions in a food propensity questionnaire. ${ }^{14}$

Moreover, the methods/questionnaires used for data collection would need to be adapted to the objectives of the analysis of interest. For instance, if the objective is to estimate usual intake to assess current continuous food supplement (including PFS) consumption, then the questionnaire should include the most appropriate assessment method that best collects these data, e.g. a food frequency questionnaire; the choice of the method often determined by previously mentioned limitations. Another example is seen in the evaluation of the risk of toxicity; the questionnaire should be adapted to collect consumption of the maximum amount taken over a short period of time, so as to best assess this level of risk.

\subsection{Intake estimation of food nutrients and of PFS ingredients}

A parallelism can be established between the intake estimation of food nutrients and that of PFS ingredients: nutrients are to foods as plant active ingredients, also known as phytochemicals, are to PFS. In this way, nutrients would be considered the composition units of foods and plant active ingredients would be the composition units of PFS.

The intake estimation process can be summarised in the following steps:

1. The individual consumption data (either of food or of PFS) is collected through the most suitable assessment methods and administration techniques described in section 2.1.

2. These data are then analysed in terms of their nutrient or active ingredient composition by means of a food composition database (or food composition tables), which will allow to obtain an estimate of the total intake of nutrients (e.g. grams of protein, micrograms of folate, $\mathrm{mg}$ of calcium, etc.) or of the total intake of active ingredients (e.g. $\mathrm{mg}$ of lycopene, $\mathrm{mg}$ of cynarin, mg of hypericin, micrograms of alliin, etc.) derived from the consumption of foods and dietary supplements (including PFS).

Regarding the composition databases/tables used in the intake estimation, there are numerous composition databases/tables available that can be used for the estimation of nutrient intake, both at the local/national and international levels. However, in the case of FS (including PFS), there are only few of very recent or on-going elaboration; a good example is the USDA's Dietary Supplement Ingredient Database (DSID), used to evaluate levels of ingredients in dietary supplement or FS products (including botanically-based supplements). ${ }^{15}$ The need exists for the elaboration, as part of nutrition surveys, of more dietary supplement composition databases, in particular of PFS ingredients. With the help of these composition databases, consumed PFS and plant-type foods could be analysed in terms of their active ingredients and added together in order to come up with the total intake of plant-derived active ingredients (e.g. the lycopene contained in a PFS - at a high concentration per dose - plus the lycopene contained in a tomato - at a much lower concentration) at the individual level for a PFS risk-benefit assessment at a later stage.

\subsection{The near future: PlantLIBRA's plant food supplement consumption survey - characteristics and assessment methodology requirements}

Bearing in mind the dietary survey methods described and the previous studies that have or have not used them, the logical question to follow would be: what would be the PFS consumption assessment methods of choice and how would future studies be designed to include them?

The European project PlantLIBRA, has among many others, the task of conducting a European PFS consumption survey, for which different methods to collect data have been selected and 
Table 2 Prevalence data of selected European studies evaluating PFS or Complementary and Alternative Medicines (CAM) usage

\begin{tabular}{|c|c|c|c|c|c|c|}
\hline $\begin{array}{l}\text { Author (year } \\
\text { publication) }\end{array}$ & $\begin{array}{l}\text { Country (year } \\
\text { fieldwork) }\end{array}$ & PFS User Definition & $\begin{array}{l}\text { Sample } \\
\text { characteristics }(n)\end{array}$ & $\%$ Use & $\%$ Women & $\%$ Men \\
\hline $\begin{array}{l}\text { Fundación Salud y } \\
\text { Naturaleza }(2007)^{6}\end{array}$ & Spain (2005-2006) & $\begin{array}{l}\text { Medicinal plant ever } \\
\text { use }\end{array}$ & $\begin{array}{l}\text { Adults, } \\
\text { representative } \\
\text { national sample } \\
\text { (417) }\end{array}$ & $\begin{array}{l}70 \% \text { ever use; } 30 \% \\
\text { habitual users }\end{array}$ & na & na \\
\hline $\begin{array}{l}\text { Messerer M } \\
(2001)^{27}\end{array}$ & Sweden (1996-1997) & $\begin{array}{l}\text { Natural medicine } \\
\text { (defined by subject) } \\
\text { use within past } 2 \mathrm{wks}\end{array}$ & $\begin{array}{l}\text { Representative } \\
\text { national sample } \\
(11561)\end{array}$ & na & 14 & 7 \\
\hline $\begin{array}{l}\text { Nilsson M, et al. } \\
(2001)^{30}\end{array}$ & Sweden (1999) & $\begin{array}{l}\mathrm{CAM}^{a} \text { : biological } \\
\text { products, vit } \& \\
\text { minerals not } \\
\text { prescribed by a MD } \\
\text { in last } 2 \text { weeks }\end{array}$ & $\begin{array}{l}\text { Adults, } \\
\text { Representative } \\
\text { national sample, } \\
\text { North Sweden } \\
\text { MONICA cohort } \\
\text { (5794) }\end{array}$ & na & 23.9 & 13.3 \\
\hline Nielsen M $(2005)^{31}$ & Denmark (2000) & $\begin{array}{l}\text { natural medicine } \\
\text { (defined by subject) } \\
\text { use within past } 2 \text { wks }\end{array}$ & $\begin{array}{l}\text { Adults, } \\
\text { representative } \\
\text { national sample } \\
(16690)\end{array}$ & 14.5 & 18 & 11 \\
\hline $\begin{array}{l}\text { Menniti-Ippolito } \\
(2002)^{23}\end{array}$ & Italy (1999) & $\begin{array}{l}\text { Herbal medicine use } \\
\text { in previous } 3 \text { years }\end{array}$ & $\begin{array}{l}\text { Adults, } \\
\text { Representative } \\
\text { national sample } \\
(70 \text { 898) }\end{array}$ & na & 5.9 & 3.7 \\
\hline Thomas K (2001) & England (1998) & $\begin{array}{l}\text { Lifetime use \& use in } \\
\text { past year of } \\
\text { practitioner based } 6 \\
\text { CAM therapies } \\
\text { (herbal medicine) + } \\
\text { OTC }{ }^{b} \text { purchase of } \\
\text { herbal and } \\
\text { homeopathic } \\
\text { remedies }\end{array}$ & $\begin{array}{l}\text { Adults, } \\
\text { Representative } \\
\text { national sample } \\
\text { (2669) }\end{array}$ & $\begin{array}{l}\text { Overall Prescribed } \\
\text { CAM +OTC use: } \\
28.3 \text { in past year; } \\
46.6 \text { Lifetime use. } \\
\text { Prescribed Herbal } \\
\text { medicine: Past year- } \\
\text { 0.9; Lifetime use-4.4. } \\
\text { OTC herbal remedy: } \\
\text { Past year-19.8; } \\
\text { Lifetime use-31.4 }\end{array}$ & $\begin{array}{l}\text { All known use of any } \\
\text { 6 CAM therapies: } \\
\text { 12.5; All known } \\
\text { OTC use: } 32.6\end{array}$ & $\begin{array}{l}\text { All known use of any } \\
6 \text { CAM therapies: } \\
\text { 8.8; All known OTC } \\
\text { use: } 12.0\end{array}$ \\
\hline
\end{tabular}

combined in order to come up with a methodology that collects as much information on PFS consumption as possible. In this way, consumption of PFS by adults from 6 European countries including Finland, Germany, Italy, Romania, Spain and the United Kingdom will be assessed.

Assessment methods and administration techniques of the plantLIBRA european PFS consumption survey. A cross-sectional retrospective method (consisting of two questionnaires: a screening and a main questionnaire) will be utilised to evaluate the habitual consumption of PFS in the last 12 months on an individual level. This method will allow for the collection of data relating to the level of intake, some specific characteristics of each PFS consumed such as brand and manufacturer of PFS, the type of botanical preparations consumed as well as the frequency, seasonality and duration of consumption of individual PFS over the last 12 months and over the lifespan. Sources of information about PFS, source of recommendations and the most frequent reasons for use of these products will also be assessed.

The PFS screening questionnaire will be administered in person (face-to-face) or by telephone. A trained interviewer is more likely to convert a non-response to the survey compared to a postal administration mode. A PFS product list will also be facilitated to the interviewers for training on PFS consumer identification and classification.

One part of the main PFS consumption questionnaire includes a section that asks for the last time each reported PFS product was consumed (last $24,72 \mathrm{~h}$, etc) by the respondent. In this manner, the accuracy of reporting for each PFS product will be gauged, particularly the dose and frequency employed, so as to facilitate the subsequent benefit-risk assessment of PFS consumption.

The cost-effective collection of additional data from the same subjects at the same time has been considered when designing this 
methodology; additional information of this nature may significantly enhance the interpretation of the PFS data. Thus, the main questionnaire will also collect data about the respondent's general health, anthropometric characteristics, and dietary and lifestyle habits. Biological samples for the determination of important biomarkers will not be collected as part of this survey. However, other tasks within the PlantLIBRA project that are dealing with toxicity of PFS will collect this type of data.

An open-ended record of PFS products consumed during 7 days is to be utilised in a subsample of 50 individuals that will be previously administered a PFS questionnaire. The 7-day record will be conducted twice by each subject with a period of 6 months separating the two records.

\section{Assessment of PFS high and low intakes}

The PFS consumer seeks the attainment of a given health benefit, be it in the form of an improvement of his/her immune capacity, emotional state and gastrointestinal health, among others, when deciding to start a botanical therapy. Every consumer has clear expectations when acquiring a certain supplement and achieving their accomplishment depends not only on the supplement per se but also on the adequacy of the recommended dose, following the guidelines based on the available scientific publications for each product. As PFS products have an herbal origin and are not distributed with a health claim, no obligation exists to test their effectiveness with clinical studies and, up to now the legal basis for their production and distribution is often ambiguous. Thus, their consumption may be inadequate due to the ambiguous information received: firstly they can be purchased over the counter with no prescription needed (the consumer does not receive information or advice on the most suitable treatment frequency or duration for the desired health purpose), including any advice provided by the vendor (be it by internet or in the supermarket); secondly, its botanical origin obtained from plant extracts give PFS an aura of being innocuous with no risk of adverse effects or harmful interactions with other medical therapies or supplements, thus making it unnecessary to inform their doctors about their consumption. Finally, the insufficient information received may cause an inadequate use of the product, thus interrupting the treatment due to the absence of clear benefits or to a lack of feedback by a given expert on the benefits obtained.

PFS dosage depends on the type of product and the expected health benefit associated to its consumption. Adequate information about these issues should be provided on the product label. As PFS are not considered as medicines, the legal basis for their distribution is different to that of medications. In most occasions the certainty of PFS benefits and safety are based on a presumption of efficacy and safety. ${ }^{16}$ When the product has a long tradition of consumption and epidemiological data exist about their safety, no additional studies are required. In other situations, more studies are needed to test its efficacy and safety.

Regarding PFS efficacy, few rigorously controlled trials exist that demonstrate their efficacy. One of the PFS with more scientific backing is Echinacea in relation to its function in improving immunity for the prevention and treatment of the common cold. In brief, the numerous randomized studies, systematic reviews and meta-analysis indicate that a likely benefit exists, albeit small, due to the pharmacological activity of Echinacea. ${ }^{17-19}$ Unfortunately, certain controversy has been generated about these results. As Hart et al. ${ }^{20}$ discussed regarding the results obtained from three meta-analyses on the efficacy of Echinacea in the prevention and treatment of common cold, the methodology followed in a systematic review (search strategy, inclusion and exclusion criteria, data analysis, etc.) have a key effect on the results and conclusions obtained. Although the number of studies investigating the efficacy of PFS has been increasing, most of the studies conducted before the 1990's were supported by the industry, and others were not clearly randomized or blinded. ${ }^{21}$

For those PFS with evidence based efficacy, a step further is needed to investigate and determine the adequate intake of the product to achieve the benefits and avoid the risks of its ingestion. A minimum level of intake under which no beneficial effect is shown and an upper level limit obtained from risk-effect studies for which, taking into account the different responses to the product for certain population groups, no adverse effect is shown. As this information is available, PFS consumption surveys will permit the evaluation of the consumption at an individual and population level, and the analysis of whether consumption is adequate or falls below or above the recommendations. To succeed in obtaining this information, in-depth information about commercialised products and their formulation is needed. One of the key challenges is to determine which chemical components of the PFS are responsible for the beneficial health effect under study. Regarding Echinacea, the evidence indicates that several of its components can have a role in its immunological effect (essential oils, alkylamides, caffeic acid derivatives, polyalkynes, polyalkenes and polysaccharides), acting alone or in combination. ${ }^{22}$ Any research conducted with the aim of evaluating the health effects of botanical products will have to take into account the variability of the plant composition due to the geographical origin of the plant, the climate conditions, period of the year harvested, etc. Similar to PFS research, nutritional epidemiology has dealt with equivalent challenges: standardizing food composition when developing food composition tables, defining the macro and micronutrients responsible for a certain food's health effect, defining the best method to estimate food intake and food patterns, establishing recommended upper and lower level of intakes, etc.

Until all these uncertainties are solved, the decision to consume a certain PFS depends mostly on personal beliefs about botanicals and health than on rigorous scientific evidence.

\section{PFS consumption in European countries}

The popularity of herbal supplements and FS is on the rise in Europe and other parts of the world, with increased use in the general population as well as among specific subgroups encompassing children and pregnant women or those suffering from diseases such as cancer. ${ }^{23-26} \mathrm{~A}$ Swedish study showed that during the 1980s, the use of natural remedies, as defined by the study subject, increased dramatically, augmenting by threefold and surpassing the rise in dietary supplement use defined as vitamins or other "strengthening medicines". ${ }^{27}$

A recent systematic review evaluating the demographic characteristics and health status factors associated with 
Complementary and Alternative Medicine (CAM) use demonstrated that the majority of population based consumption studies had been conducted in the USA ( $64 \%$ of the 110 identified studies). $13 \%$ of the community-based studies were realised in Europe, the majority carried out in Scandinavia $(7 \%)$ and the UK $(5 \%){ }^{25}$

Table 2 shows data for selected European population-based studies evaluating the prevalence of PFS or related CAM therapies. People who employ CAM tend to be middle aged (in a broad sense of the definition), with a higher level of education and of female gender. However, differences were noted across studies, which may in part be due to distinct methodologies as well as variations in health beliefs and health behaviour from country to country. The European surveys show a wide range of prevalence data ranging from $0.8 \%$ to $70 \%$. Data from the USA NHANES show a prevalence for data collected in 1999-2000 of $52 \%$, applying the definition of any category of dietary supplement used in the past month, with women having a higher prevalence than men $\left(56.7 \%\right.$ vs. $46.9 \%$, respectively). ${ }^{13} \mathrm{~A}$ multicountry nationally representative study in 10 countries, the European Prospective Investigation into Cancer and Nutrition (EPIC), showed that the mean percentage of dietary supplement use varied almost 10 -fold among women and even more among men. There was a clear north-south gradient in use, with a higher consumption in northern countries. The lowest crude mean percentage of use was found in Greece (2.0\% among men, $6.7 \%$ among women), and the highest was in Denmark (51.0\% among men, $65.8 \%$ among women). ${ }^{28}$ However, the assessment method applied consisted of a standardized computerized 24 hour dietary recall of one day, which does not obtain sufficient information to yield valid estimations of usual supplement use.

The heterogeneity of definitions, study design and objectives make it difficult to compare results and to extrapolate conclusions. The majority of studies have not focussed specifically on PFS consumption but rather CAM use. CAM involves a range of therapies that include herbal medicine, naturopathy and homeopathy, among others, in which practitioners may advocate the use of food or herbal supplements. The ambiguity of categories such as "natural medicine", "herbal remedies" or "herbal medicine" and what constitutes "dietary supplements" makes it nearly impossible to attain reliable estimates of the prevalence of PFS consumption.

For the PlantLIBRA multi-country survey on PFS consumption, the PFS consumer has been defined as follows: "Any person aged 18 years and over whose consumption of PFS in the last 12 months complies with at least one of the following options:

a) $1 \mathrm{PFS}$; in the right form (tablets/pills/lozenges, soft gel capsules/pearls, hard capsules, liquid -extract/syrup/drops, sachets/packets, ampoules); at a minimum average frequency of 1 daily dose; and for at least 2 weeks non-consecutively.

b) 1 PFS, in the right form (tablets/pills/lozenges, soft gel capsules/pearls, hard capsules, liquid-extract/syrup/drops, sachets/packets, ampoules), at a minimum average frequency of 1 or more doses per week and for at least 3 weeks consecutively.

c) $1 \mathrm{PFS}$, in the right form (tablets/pills/lozenges, soft gel capsules/pearls, hard capsules, liquid-extract/syrup/drops, sachets/packets, ampoules), at a minimum average frequency of 1 or more doses per week and for at least 4 weeks nonconsecutively. d) 2 or more different PFS, in the right form (tablets/pills/ lozenges, soft gel capsules/pearls, hard capsules, liquid-extract/ syrup/drops, sachets/packets, ampoules), at a minimum average frequency of 1 or more doses per week, and the SUM of the consumption period of the 2 or more products is equal to at least 4 weeks".

\subsection{PlantLIBRA contribution}

As mentioned in the previous sections, the European Commission-funded PlantLIBRA project has addressed the abovementioned limitations in estimating PFS consumption in their incorporation of an activity to conduct a multi-country survey applying harmonised methodologies in the estimation of PFS usage. The aim is to obtain the most valid PSF intake data so as to estimate risk benefit of PFS consumption.

\section{Conclusions}

The use of herbal supplements is on the rise around the world and the herbal market is growing due to the interest of consumers in their health and well being. Moreover, distribution channels have experienced important changes, particularly by increasing e-commerce and direct sales. As a consequence, the harmonisation of substances other than vitamins and minerals, especially plants extracts, constitutes an important area that needs to be addressed in Europe. Specific rules concerning plant preparations used as ingredients of FS need to be developed according to evidence based data. Although different market research exists for the European herbal market, these data are not easily accessed.

There are many difficulties associated with PFS research, in particular with establishing standardised concepts and definitions and with the choice of methodologies to assess botanical/ plant food supplement consumption at the individual level. Dietary consumption assessment methods are being used as a starting point, but as they are at present, they cannot detect consumption of PFS. They can be used to readapt and redesign assessment methods more suitable for PFS consumption. The intake estimation process of food nutrients (using composition databases/tables) can be used as a guideline in the proposal of an intake estimation process of PFS ingredients. More dietary supplement composition databases are needed, in particular of PFS, so that intake of these products' ingredients can be estimated from consumption data. The European project PlantLIBRA is conducting a European PFS consumption survey whose assessment methodology follows these guidelines of readapting and redesigning existing dietary assessment methods to a the new research area opened to PFS and their data information requirements.

\section{Acknowledgements}

The research leading to these results has received funding from the European Community's Seventh Framework Programme (FP7/2007-2013) under grant agreement $\mathrm{n}^{\circ}$ 245199. It has been carried out within the PlantLIBRA project (website: www. plantlibra.eu). This report does not necessarily reflect the Commission views or its future policy on this area. 


\section{Notes and references}

1 European Parliament, Official Journal, L 183 of 12.7.2002.

2 M. J. Tallon, The Dietary Supplements Regulatory and Market Outlook: Market report, Business Insights, 2011.

3 Global Industry Analysts, Herbal supplements and remedies: Market research report, 2011.

4 European Advisory Services (EAS), Study carried out on behalf of the European Commission, Service contract $n^{\circ}$ SANCO/2006/E4/018, 2007.

5 Real Decreto 1487/2009, de 26 de septiembre, relativo a los complementos alimenticios (Royal decree on food supplements), BOE NUM 244 of 9.10 .2009 .

6 Fundación Salud y Naturaleza, Libro Blanco de los herbolarios y las plantas medicinales (White Book of herbal shops and medicinal plants), Fundación Saludy Naturaleza, Madrid, Spain, 2007, pp. 69-89.

7 U.S. Department of Health and Human Services (DHHS), National Center for Health Statistics, Third National Health and Nutrition Examination Survey, 1988-94, Series 11 Number 1A. ASCII Version. Hyattsville, MD: Centers for Disease Control and Prevention, 1997. Available from the National Technical Information Service (NTIS), Springfield, VA.

8 P. M. Barnes, B. Bloom and R. Nahin, CDC National Health Statistics Report \#12. Complementary and Alternative Medicine Use Among Adults and Children: United States, 2007. December 2008. Available online: http://nccam.nih.gov/news/camstats/2007/ (accessed 22 July, 2011).

9 Slone Survey. Available online: http://www.bu.edu/slone/ SloneSurvey/SloneSurvey.htm (accessed 22 July, 2011).

10 PlantLIBRA project, available at: http://www.plantlibra.eu/web/ (access date 18 April 2011).

11 L. Serra-Majem, L. Ribas-Barba and J. Aranceta-Bartrina, in Nutrición y Salud Pública. Métodos, Bases científicas y Aplicaciones, ed. L. Serra-Majem and J. Aranceta-Bartrina, Masson, Barcelona, 2nd edn, 2006, pp. 136-145.

12 R. S. Gibson, in Principles of Nutritional Assessment, Oxford University Press, London, 2nd edn 2005.

13 K. Radimer, B. Bindewald, J. Hughes, B. Ervin, C. Swanson and M. F. Picciano, Am. J. Epidemiol., 2004, 160, 339-349.
14 European Food Safety Authority (EFSA), EFSA Journal, 7, 1435. Available online: www.efsa.europa.eu.

15 United States Department of Agriculture (USDA), Agricultural Research Service (ARS): Dietary Supplement Ingredient Database (DSID). Available online: http://ars.usda.gov/Aboutus/docs.htm? docid $=6255$.

16 European Food Safety Authority (EFSA) - Scientific Committee, EFSA Journal, 2009, 7, 280. Available online: www.efsa.europa.eu.

17 R. Schoop, P. Klein, A. Suter and S. L. Johnston, Clin. Ther., 2006, 28, 174-183.

18 K. Linde, B. Barrett, K. Wölkart, R. Bauer and D. Melchart, Cochrane Database Syst. Rev., 2006, 25, CD000530.

19 S. A. Shah, S. Sander, C. M. White, M. Rinaldi and C. I. Coleman, Lancet Infect. Dis., 2007, 7, 473-480.

20 A. Hart and P. Dey, Prev. Med., 2009, 49, 78-82.

21 B. Barrett, M. Vohmann and C. Calabrese, Journal of Family Practice, 1999, 48, 628-635.

22 D. V. C. Awang and D. G. Kindack, Can. Pharm. J., 1991, 124, 512-516.

23 F. Menniti-Ippolito, L. Gargiulo, E. Bologna, E. Forcella and R. Raschetti, Eur. J. Clin. Pharmacol., 2002, 58, 61-64.

24 M. R. Ritchie, Proc. Nutr. Soc., 2007, 66, 479-482.

25 F. L. Bishop and G. T. Lewith, Evidence-Based Complementary Altern. Med., 2010, 7, 11-28.

26 J. Adams, C. W. Lui and D. Sibbritt, Birth, 2009, 36, 237-245.

27 M. Messerer, S. E. Johansson and A. Wolk, J. Intern. Med., 2001, 250, 160-166.

28 G. Skeie, T. Braaten, A. Hjartåker and M. Lentjes, Eur. J. Clin. Nutr., 2009, 63, S226-S238.

29 B. Hanssen, S. Grmsgaard, L. Launso, V. Fonnebo, T. Falkenberg and N. K. Rasmussen, Scand. J. Prim. Health Care, 2005, 23, $57-62$.

30 M. Nilsson, G. Trehn and K. Asplund, J. Intern. Med., 2001, 250, 225-233.

31 M. W. Nielsen, E. H. Hansen and N. K. Rasmussen, Ann. Pharmacother., 2005, 39, 1534-1538.

32 K. J. Thomas, J. P. Nicholl and P. Coleman, Complement. Ther. Med., $2001,9,2-11$.

$33 \mathrm{~K}$. Thomas and P. Coleman, J. Public Health, 2004, 26, 152-157. 